\title{
Characterisitcs of Saccharomyces boulardii for reducing ammonia emission from livestock manure
}

\author{
Sun $I I \mathrm{Kim}^{1 \dagger}$, Wan Heo ${ }^{2 \dagger}$, So Jung Lee ${ }^{1}$, Bok Kyung Han ${ }^{1}$, Hong Gu Lee ${ }^{3}$ and Young Jun Kim ${ }^{*}$ (1)
}

\begin{abstract}
Ammonia from livestock manure acts as a precursor to produce particulate matter (PM) by reacting with atmospheric chemical components volatilized from various sources. Ammonia itself acts as a toxic substance to human health, and thus has direct or indirect adverse effects on human health. This study aimed to verify the effectiveness and mechanism of action of Saccharomyces boulardii (SB) in reducing the ammonia emission from livestock manure. The specific ability of SB was confirmed through comparative verification with S. cerevisiae (SC) belonging to the same genus. SB and SC could use $50 \%$ of ammonia-nitrogen as inorganic nitrogen source in minimal medium. In the control group, the $\mathrm{pH}$ level of manure was significantly increased compared to the $\mathrm{pH}$ level at $\mathrm{O} \mathrm{h}$, and the DNA concentration of Proteus mirabilis, which increase the manure $\mathrm{pH}$ through ammonia production, was found to increase by 2.7-fold. Significant decrease in $\mathrm{pH}$ and proliferation of $P$. mirabilis was found in SB group compared to control $(p<0.05)$. The SB group also reduced the amount of ammonia emitted from manure by $25 \%$ for 35 days. These results suggested that $\mathrm{SB}$ contributed to reducing ammonia emission from manure by reducing $\mathrm{pH}$ and inhibiting $\mathrm{HAB}$ as well as removing ammonia-nitrogen. Accordingly, SB as a microbiological agent is expected to contribute not only to reduce ammonia emission but also to improve manure quality as a fertilizer.
\end{abstract}

Keywords: Ammonia emission, Fine dust, Livestock manure, Yeast

\section{Introduction}

Ammonia, which acts as a precursor of fine dust, is exhausted in gaseous form and reacts with $\mathrm{NO}_{\mathrm{x}}$ and $\mathrm{SO}_{\mathrm{x}}$ in the atmosphere to produce ammonium nitrate and ammonium sulfate, respectively, which are particulate fine dusts [1]. The fine dust which is produced by the reaction of ammonia has a longer residence time in the atmosphere than other air pollutants, and thus there is a risk of spreading further causing more serious health problem [1]. Ammonia itself enters the human body and directly causes various diseases through toxic effects. According to the most recent statistical reports from the

\footnotetext{
*Correspondence: yk46@korea.ac.kr

tsunll Kim and Wan Heo contributed equally to this work

1 Department of Food and Biotechnology, Korea University, Sejong 30019,

Republic of Korea

Full list of author information is available at the end of the article
}

Ministry of Environment of European Union and South Korea, majority of the ammonia emission is from agricultural sector $(>80 \%)$. Of the $80 \%$, livestock manure occupies the largest proportion [2,3]. Livestock manure is characterized by large quantities of ammonia production and gas emissions through the action of microorganisms having urease and deaminase activities [4-7]. In addition, ammonia reacts with water to increase $\mathrm{pH}$ levels by dissociation of hydroxide ions, thereby increasing gaseous ammonia conversion and emission $[8,9]$.

Research on the management of ammonia gas emission has been conducted worldwide in order to reduce fine dust [10]. Reducing methods, such as acidification, adsorption, and addition of biological materials, as well as physical methods of collecting ammonia gas in livestock facilities, have been described [11, 12]. Among these, various studies employing microorganisms have 
been conducted because the reduction technology using microbes is economical and shows a lower incidence of secondary pollution problems than physical or chemical methods which can cause the secondary pollution problem such as soil acidification and eutrophication. However, most studies have focused on ammonia or liquid manure to reduce odors and harmful gases from the perspective of workers, and there have been insufficient studies concerning atmospheric ammonia emissions and solid manure.

Yeasts of the genus Saccharomyces are known to synthesize amino acids using organic and inorganic nitrogen sources [13-15]. Among them, S. boulardii (SB) is used as a biological therapeutic agent and a feed additive to increase livestock productivity [16-18]; additionally, it is a probiotic yeast that produces organic acids. Moreover, it has higher stability under acidic and high-temperature conditions compared to S. cerevisiae (SC) [19-21]. Furthermore, it has been reported that metabolites of SB inhibit the growth of intestinal pathogenic microorganisms such as Clostridium difficile and Salmonella, while increasing the growth of beneficial bacteria such as lactic acid bacteria [16, 17, 22]. Given these capacities, SB may have potential efficacy in the inhibition of harmful ammonia-producing bacteria and pathogens. This study intended to confirm the unprecedented application of a biological agent to reduce ammonia emissions by treating livestock manure with SB.

\section{Materials and methods}

\section{Manure sample and microorganisms}

Manure was collected from a livestock barn in Anseong, Korea. Samples were prepared by mixing $50 \%$ swine manure, $10 \%$ cattle manure, $10 \%$ poultry manure, and $30 \%$ sawdust and then used for analysis. All experiments were performed with SB (CNCM I-1079) obtained from LALLEMAND Inc. (Montreal, Canada). SC (KCTC 7107) was purchased from KCTC (Korean Collection for Type Cultures, Daejeon, Korea) and used for comparative analysis with SB belonging to the same genus. Proteus mirabilis (KCTC 2510), purchased from KCTC, was used for genomic quantification of ammonia-producing bacteria in manure.

\section{Microbial growth conditions}

Yeasts, at an inoculum size of $2 \%(\mathrm{v} / \mathrm{v})$, were inoculated in yeast extract peptone dextrose (YPD, Difco ${ }^{\mathrm{TM}}$, Detroit, MI, USA) medium containing $0.1 \%(\mathrm{v} / \mathrm{v})$ penicillin-streptomycin solution (Hyclone ${ }^{\mathrm{TM}}$, Logan, Utah, USA). The medium was sterilized for $15 \mathrm{~min}$ at $121{ }^{\circ} \mathrm{C}$, and yeasts were cultured in a microbial incubator (JSRI$250 \mathrm{~T}$, Gongju, Korea) at $30{ }^{\circ} \mathrm{C}$. P. mirabilis was grown in nutrient broth $\left(\mathrm{NB}, \operatorname{Difco}^{\mathrm{TM}}\right)$ at $37{ }^{\circ} \mathrm{C}$, in a microbial incubator. All microorganisms were used in the experiments after subculturing three times or more.

\section{Analysis of rate of ammonia removal by yeasts in minimal medium}

To verify the ammonia removal activity of yeasts in the minimal medium, 2\% (w/v) glucose (Oriental Chemical Industries Co., Ltd., Seoul, Korea) was used as the carbon source, and $1 \%(\mathrm{w} / \mathrm{v})$ ammonium chloride (Fisher Scientific International, Inc., Pittsburgh, Pennsylvania, USA) was used as the nitrogen source. After dissolving glucose and ammonium chloride in yeast nitrogen base (YNB) without amino acids and ammonium sulfate (Difco ${ }^{\mathrm{TM}}$ ), yeasts (SB and SC) were inoculated at an inoculum size of $2 \%(\mathrm{v} / \mathrm{v})$ and incubated with shaking at $30{ }^{\circ} \mathrm{C}$ and $130 \mathrm{rpm}$ for $24 \mathrm{~h}$. The yeast cultures were centrifuged at $4{ }^{\circ} \mathrm{C}$ and $10,000 \times g$, and the supernatant was used for the determination of ammonium nitrogen concentration via the indophenol method [23].

\section{DNA extraction and qPCR}

DNA extraction was performed using a Fast DNA spin kit for soil (MP Biomedicals, Santa Ana, California, USA), and DNA concentrations were measured using a NanoDrop ND-1000 (Thermo Fisher Scientific, Waltham, Massachusetts, USA). The primers used in this study are listed in Table 1 [24-27]. qPCR analysis was modified by referring to the research of Bokulich et al. [28]. In particular, qPCR amplification was performed in $20 \mu \mathrm{L}$ final volumes containing $8 \mu \mathrm{L}$ of DNA $(2.5 \mathrm{ng} / \mu \mathrm{L}), 1 \mu \mathrm{L}$ each of forward and reverse primers $(10 \mathrm{pmol})$, and $10 \mu \mathrm{L}$ of $2 \times$ GoTaq $^{\circledR}$ qPCR Master mix (Promega, Wisconsin, USA). Amplification was carried out using a 7500 RealTime PCR System (Applied Biosystems, Waltham, MA, USA). The reactions were run for 45 cycles: pre-denaturation at $95^{\circ} \mathrm{C}$ for $10 \mathrm{~min}$, denaturation at $95^{\circ} \mathrm{C}$ for $15 \mathrm{~s}$, and annealing and extension at $60^{\circ} \mathrm{C}$ for $1 \mathrm{~min}$. For meltcurve analysis, the process was performed at $95{ }^{\circ} \mathrm{C}$ for $15 \mathrm{~s}, 60^{\circ} \mathrm{C}$ for $1 \mathrm{~min}$, and $95^{\circ} \mathrm{C}$ for $30 \mathrm{~s}$. Standard curves for quantifying the amount of microbial DNA were created by plotting the cycle threshold $(\mathrm{Ct})$ values of the qPCR performed against a dilution series of the extracted DNA of the microbial pure cultures (Fig. 1).

\section{Analysis of yeast growth characteristics}

For the analysis of growth of SB and SC in livestock manure, $1 \mathrm{~g}$ of livestock manure and $5 \mathrm{~mL}$ of distilled water were mixed; $160 \mu \mathrm{L}$ of the pure culture solution was inoculated into this mixture to confirm the change in DNA proportion according to the incubation for $24 \mathrm{~h}$. Aerobic culture conditions were maintained by shaking the culture at $30^{\circ} \mathrm{C}$ and $130 \mathrm{rpm}$, and MGC AnaeroPack 
Table 1 List of PCR primer pairs used for qPCR

\begin{tabular}{|c|c|c|c|c|}
\hline Target strain & Primer name & Sequence $\left(5^{\prime}-3^{\prime}\right)$ & Product size (bp) & References \\
\hline \multirow[t]{2}{*}{ Universal yeast } & YEASTF & GAGTCGAGTTGTTTGGGAATGC & 124 & {$[24]$} \\
\hline & YEASTR & TCTCTTTCCAAAGTTCTTTTCATCTTT & & \\
\hline \multirow[t]{2}{*}{ Saccharomyces cerevisiae } & SCDF & AGGAGTGCGGTTCTTTG & 310 & {$[25]$} \\
\hline & SCDR & TACTTACCGAGGCAAGCTACA & & \\
\hline \multirow[t]{2}{*}{ Total bacteria } & TBF & CGGTGAATACGTTCCCGG & 142 & [26] \\
\hline & TBR & TACGGCTACCTTGTTACGACTT & & \\
\hline \multirow[t]{2}{*}{ Proteus mirabilis } & ureRF & GGTGAGATTTGTATTAATGG & 225 & {$[27]$} \\
\hline & ureRR & ATAATCTGGAAGATGACGAG & & \\
\hline
\end{tabular}
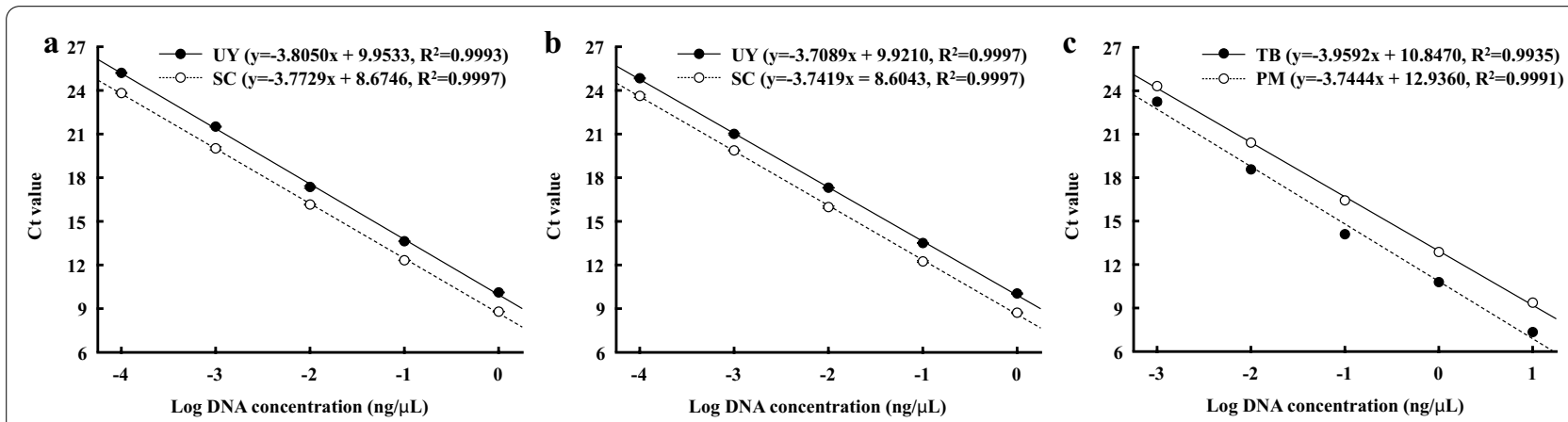

Fig. 1 Linear correlation between the log of genomic DNA concentration and Ct values from qPCR. Each reaction was performed in triplicate. UY, universal yeast; SC, Saccharomyces cerevisiae; PM, Proteus mirabilis. a DNA of Saccharomyces boulardii CNCM I-1079 pure culture, b DNA of Saccharomyces cerevisiae KCTC 7107 pure culture, c DNA of Proteus mirabilis KCTC 2510 pure culture

(Mitsubishi Gas Chemical Co., Tokyo, Japan) was used at $30{ }^{\circ} \mathrm{C}$ under anaerobic condition.

\section{Analysis of changes in $\mathrm{pH}$ and growth of hyper ammonia-producing bacteria (HAB) in livestock manure} For analysis of $\mathrm{pH}$ change and $\mathrm{HAB}$ growth after treatment with SB and SC, $100 \mu \mathrm{L}(6.80 \log$ CFU) of SB and $\mathrm{SC}$ pure culture was inoculated into a solution containing $50 \mathrm{~mL}$ of distilled water and $10 \mathrm{~g}$ of livestock manure. After incubation at $30{ }^{\circ} \mathrm{C}$ for $24 \mathrm{~h}$ under aerobic and anaerobic conditions, the $\mathrm{pH}$ of manure was measured, and the growth of $P$. mirabilis were confirmed through qPCR analysis.

\section{Analysis of ammonia gas emission from livestock manure} Ammonia emissions were analyzed using the air trapping system of Park et al. [29]. For analysis of ammonia gas emissions from livestock manure by treatment of yeast, $100 \mathrm{~g}$ of livestock manure sample was inoculated with $1 \mathrm{~mL}$ (7.80 $\log$ CFU) of yeast (SB and SC) to analyze changes in ammonia emissions resulting from microbial treatment. Ammonia gas emitted in the chamber was transported to a gas bubble-collecting flask containing $50 \mathrm{~mL}$ of $0.05 \mathrm{~N} \mathrm{H}_{2} \mathrm{SO}_{4}$ (95\%, Dae Jung Chemicals,
Gyeonggi-Do, Korea), through air inflow using an air pump and a gas flow meter, and trapped at the same time. Air inflow and outflow rates were maintained at $1 \mathrm{~L} / \mathrm{min}$ to analyze daily ammonia emissions.

\section{Statistical analysis}

The results of each experiment were expressed as the mean \pm SEM of triplicate experiments, and statistical analysis was performed using the SAS v.9.4 program (SAS Institute Inc., Cary, North Carolina, USA). Differences between groups were confirmed Student's $t$-test and one-way ANOVA, followed by Tukey's post hoc test with a significance level at $p<0.05$.

\section{Results and discussion}

Ammonia removal abilities of yeasts in minimal medium Reduction of ammonia gas volatilization and ammonia nitrogen concentrations using microorganisms proceeds via various mechanisms such as nitrification, denitrification, and nitrogen fixation. In addition, the metabolic ability of ammonia nitrogen, which is a source of ammonia gas, is a crucial indicator for suppressing ammonia gas emission [30-32]. SB and SC significantly reduced ammonia nitrogen compared to $0 \mathrm{~h}$ 
$(p<0.05)$ by approximately $50 \%$ in YNB medium, which is used as a minimal medium (Fig. 2), and ammonia gas volatilization was not observed in the culture medium during the experiment. This result suggested that ammonia nitrogen was metabolized to non-ammonia nitrogen in the medium without emission in gaseous form; this indicates that both the yeasts can use ammonia nitrogen as an inorganic nitrogen source.

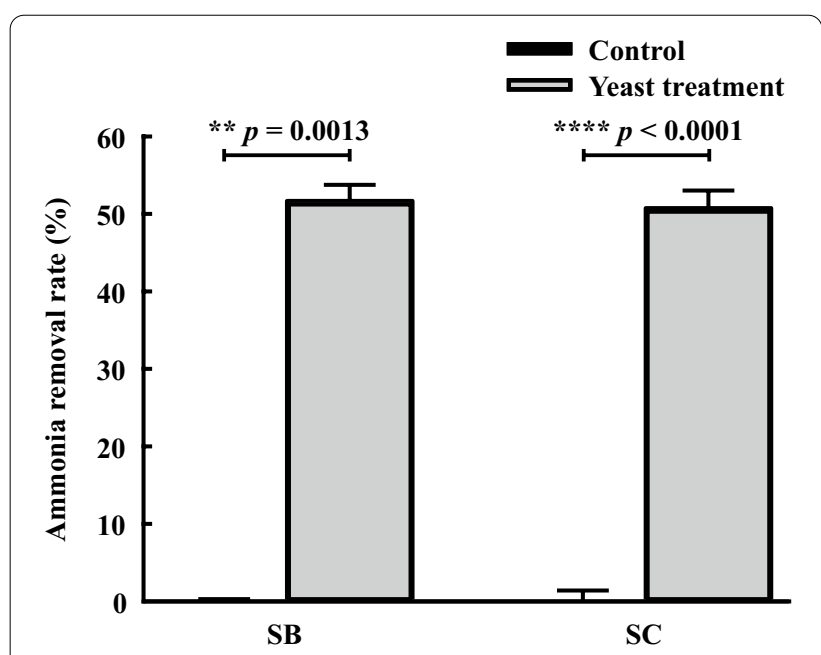

Fig. 2 Ammonia removal rate of SB and SC in YNB medium with $\mathrm{NH}_{4} \mathrm{Cl}$ as a nitrogen source in shaking culture (130 rpm). SB, Saccharomyces boulardii CNCM I-1079; SC, Saccharomyces cerevisiae KCTC 7107. Error bars represent the standard error $(n=3) .{ }^{* *} p<0.01$, ${ }^{* * * *} p<0.0001$, compared between control and yeast treatment groups, indicates statistical significance (SB treatment vs. control: $f$-value $=52.41$, degree of freedom $(D F)=2.0763, t$-value $=-24.95$, $p=0.0013 ; \mathrm{SC}$ treatment vs. control: $\mathrm{f}-\mathrm{value}=2.50, \mathrm{DF}=4$, $\mathrm{t}$-value $=-19.03, \mathrm{p}<0.0001 ; \mathrm{SB}$ vs SC treatments: $\mathrm{f}$-value $=1.21$, $\mathrm{DF}=4, \mathrm{t}$-value $=0.31, \mathrm{p}=0.7749)$

\section{Growth characteristics of yeasts in manure depending on culture conditions}

The growth of yeasts depending on the presence of oxygen in livestock manure was confirmed based on the change in the DNA ratio of both SB and SC to total yeasts (Fig. 3). Saccharomyces spp. strains are facultative anaerobic microbes capable of proliferating under both aerobic and anaerobic conditions [33, 34], and it was confirmed that SB and SC could grow in livestock manure under all tested conditions. After $24 \mathrm{~h}$ incubation, DNA proportion of SB increased from approximately $20-45 \%$ under all culture conditions (SB in aerobic condition, $p=0.0419$; SB in anaerobic condition, $p=0.0481$ ). Additionally, the DNA proportion of SC increase from 10 to $47 \%$ under aerobic condition and from 17 to $50 \%$ under anaerobic condition (SC in aerobic condition, $p=0.0002$; $\mathrm{SC}$ in anaerobic condition, $p=0.0256$ ). In the case of both SB and SC, it is expected that their growth in manure environment is possible, considering that the dominance increased 2-4 times compared to $0 \mathrm{~h}$ in the manure medium conditions.
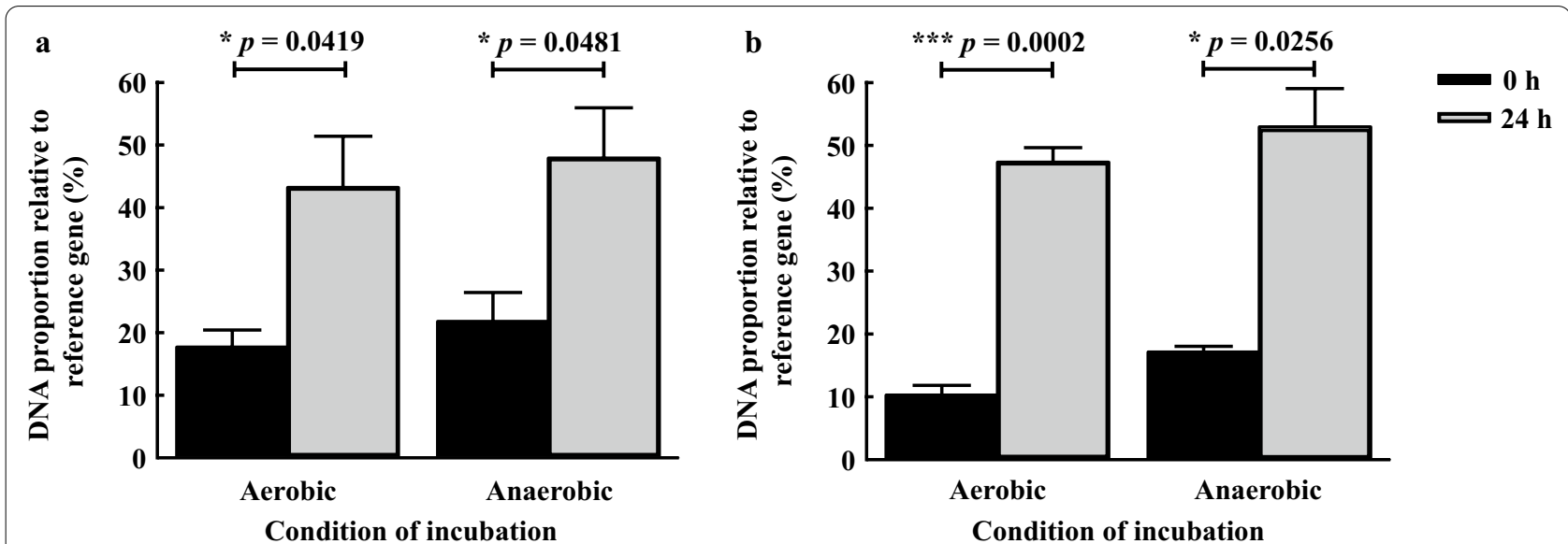

Fig. 3 Quantitative real-time PCR analysis to determine the quantity of yeast genomic DNA content relative to a universal gene after $24 \mathrm{~h}$ of incubation for analysis of DNA proportions in manure. The strains were incubated under aerobic and anaerobic conditions at $30{ }^{\circ} \mathrm{C}$. Values are the mean \pm SEM. Error bars represent the standard error $(n=3)$. a DNA proportion of Saccharomyces boulardii CNCM I-1079 (SB), b DNA proportion of Saccharomyces cerevisiae KCTC 7107 (SC). ${ }^{*} p<0.05,{ }^{* * *} p<0.001$, compared between 0 and 24 h DNA proportion in the same group and same condition, indicates statistical significance ( 0 vs. 24 h of SB in the aerobic condition: $f$-value $=9.00$, degree of freedom $(D F)=4$, t-value $=-2.95$, $p=0.0419 ; 0$ vs. $24 \mathrm{~h}$ of SB in the anaerobic condition: $f$-value $=2.98$, DF $=4$, t-value $=-2.81, p=0.0481 ; 0$ vs. 24 h of SC in the aerobic condition: $\mathrm{f}$-value $=2.22, \mathrm{DF}=4$, t-value $=-13.28, p=0.0002 ; 0$ vs. $24 \mathrm{~h}$ of SC in the anaerobic condition: $\mathrm{f}$-value $=44.65, \mathrm{DF}=2.0895, \mathrm{t}-\mathrm{value}=-5.81$, $p=0.0256)$ 


\section{Changes in $\mathrm{pH}$ and growth of $\mathrm{HAB}$ in manure by yeast treatment}

Increased ammonia concentrations enhance the $\mathrm{pH}$ by the dissociation of hydroxide ions, and the ionic and gaseous forms of ammonia are determined by changes of the $\mathrm{pH}$. For this reason, changes in ammonia concentrations and $\mathrm{pH}$ are substantial causes of ammonia gas emissions $[8,9]$. It has been reported that ammonia concentrations can be controlled by using oxidizing agents, such as iron chloride, sulfuric acid [35, 36], or various chemical compounds [5] that reduce ammonia emission from livestock manure. Furthermore, the effects of SB and SC in manure were evaluated as they possess activities of pathogen inhibition by antimicrobial peptide production and $\mathrm{pH}$ reduction [21, 37]. Indeed, Saccharomyces spp. generally produce organic acids during growth [38].

For more accurate observations of the changes in manure due to yeast growth, $\mathrm{pH}$ levels were measured after $24 \mathrm{~h}$ of incubation with liquid livestock manure under aerobic and anaerobic conditions (Table 2). The control $(p=0.0255$ compared to $\mathrm{pH}$ at $0 \mathrm{~h})$ and $\mathrm{SC}$ groups ( $p=0.0340$ compared to $\mathrm{pH}$ at $0 \mathrm{~h}$ ) under aerobic condition showed a significant increase in $\mathrm{pH}$ from the initial level of 7.34 to more than $7.40(\mathrm{pH} 7.63$ for control and $\mathrm{pH} 7.43$ for $\mathrm{SC}$ ), and the SB group exhibited a tendency to decrease $\mathrm{pH}$ by 7.14 compared to $0 \mathrm{~h}$, showing a significant difference $(p<0.05)$ compared with the control and SC groups. In the case of anaerobic condition, all groups demonstrated decreased $\mathrm{pH}$ after $24 \mathrm{~h}$.

Table 2 Change of $\mathrm{pH}$ in manure by using 2 yeasts in aerobic and anaerobic conditions

\begin{tabular}{|c|c|c|c|c|c|}
\hline \multicolumn{2}{|l|}{ Time (h) } & \multicolumn{2}{|l|}{0} & \multicolumn{2}{|l|}{24} \\
\hline Condition & Group & Average & SE & Average & SE \\
\hline \multirow[t]{3}{*}{ Aerobic } & Control & 7.34 & 0.01 & $7.63^{*} a$ & 0.05 \\
\hline & SB & 7.34 & 0.01 & $7.14^{b}$ & 0.10 \\
\hline & SC & 7.34 & 0.01 & $7.46^{*} \mathrm{a}$ & 0.02 \\
\hline \multirow[t]{3}{*}{ Anaerobic } & Control & 7.34 & 0.01 & $6.92^{* * a}$ & 0.02 \\
\hline & $\mathrm{SB}$ & 7.34 & 0.01 & $6.68^{* *} b$ & 0.07 \\
\hline & SC & 7.34 & 0.02 & $6.83^{* * *} a$ & 0.01 \\
\hline
\end{tabular}

SB, Saccharomyces boulardii CNCM I-1079; SC, Saccharomyces cerevisiae KCTC 7107

Values are the mean \pm SEM. ${ }^{*} p<0.05,{ }^{* *} p<0.01,{ }^{* * *} p<0.001$ vs. $0 \mathrm{~h}$ indicates statistical significance ( 0 vs. $24 \mathrm{~h}$ of control in the aerobic condition: degree of freedom $(D F)=2$, t-value $=-6.14, p=0.0255 ; 0$ vs. $24 \mathrm{~h}$ of SB in the aerobic condition: $\mathrm{DF}=2$, t-value $=1.98, p=0.1864 ; 0$ vs. $24 \mathrm{~h}$ of SC in the aerobic condition: $\mathrm{DF}=2, \mathrm{t}$-value $=-5.29, p=0.0340 ; 0 \mathrm{vs} .24 \mathrm{~h}$ of control in the anaerobic condition: $\mathrm{DF}=2$, $\mathrm{t}$-value $=25.40, p=0.0015 ; 0 \mathrm{vs}$. $24 \mathrm{~h}$ of $\mathrm{SB}$ in the anaerobic condition: $\mathrm{DF}=2$, $\mathrm{t}$-value $=10.06, p=0.0097 ; 0 \mathrm{vs.} 24 \mathrm{~h}$ of $\mathrm{SC}$ in the anaerobic condition: $\mathrm{DF}=2, \mathrm{t}$-value $=51.00, p=0.0004$. The different letters $(\mathrm{a}$, b) indicate statistically different groups at the same time and under the same conditions (significance level at $p<0.05$ ). There were significant differences in $\mathrm{pH}$ between three groups in the aerobic condition $[F(2,6)=14.50, p=0.0050]$ and anaerobic condition $[\mathrm{F}(2,6)=9.19, p=0.0149]$
In particular, the $\mathrm{SB}$ group showed a significant decrease $(p<0.05)$ in $\mathrm{pH}$ by 6.68 compared with the other groups (pH 6.92 for control and $\mathrm{pH} 6.83$ for SC).

It was deduced that the $\mathrm{pH}$ change pattern was reversed in the aerobic and anaerobic control groups because of the influence of microorganisms in livestock manure that increased the $\mathrm{pH}$ under aerobic condition. Vince et al. [6] reported that the representative aerobic gram-negative bacteria (Proteus spp., Escherichia coli, etc.), which produce ammonia in livestock manure, accumulate ammonia in the manure by urea hydrolysis and deamination, and these activities are affected by urea concentration and $\mathrm{pH}$ change. According to Vince et al. [6], P. mirabilis has been reported to produce more than $50 \mathrm{ppm}$ of ammonia per $100 \mathrm{ppm}$ of urea as a substrate. Likewise, it was found in our study that $P$. mirabilis, one of $\mathrm{HAB}$ strains analyzed in this study, could not grow under anaerobic condition but could proliferate under aerobic condition; 2.7-fold increase compared to initial DNA concentration in the control group (Fig. 4). In the SB group, P. mirabilis showed 1.2-fold increase in DNA concentration compared to the $0 \mathrm{~h}$, and the increase rate in DNA was significantly reduced compared to the

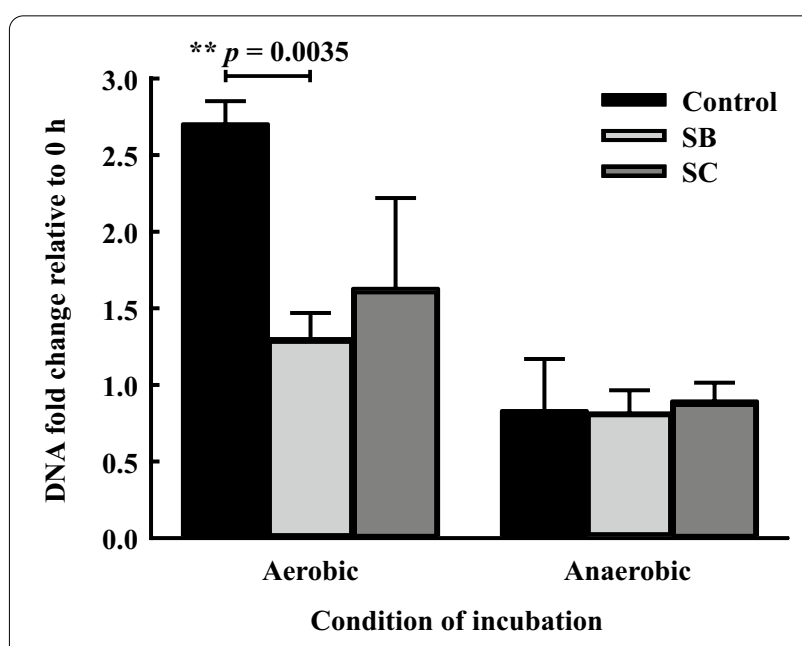

Fig. 4 Real-time PCR analysis to determine the change in genomic DNA concentration of Proteus mirabilis (P. mirabilis), which is a hyper ammonia-producing bacterium (HAB), in livestock manure by treatment with yeasts. SB, Saccharomyces boulardii CNCM I-1079; SC, Saccharomyces cerevisiae KCTC 7107. Values on the $y$-axis represent fold change in DNA levels at $24 \mathrm{~h}$ compared to DNA concentration at $0 \mathrm{~h}$. Error bars represent the standard error $(n=3) .{ }^{* *} p<0.01$, compared between control and SB in the aerobic condition, indicates statistical significance (control vs. SB in the aerobic condition: $f$-value $=1.27$, degree of freedom (DF) $=4, t$-value $=6.17, p=0.0035$; control vs. SC in the aerobic condition: $f$-value $=15.44, \mathrm{DF}=4$, $\mathrm{t}$-value $=1.76, p=0.1537$; control vs. SB in the anaerobic condition: $\mathrm{f}$-value $=5.05, \mathrm{DF}=4, \mathrm{t}$-value $=0.04, p=0.9686$; control vs. SC in the anaerobic condition: $f$-value $=7.74, D F=4$, t-value $=-0.17$, $p=0.8702)$ 
control group $(p<0.05)$. In the SC group, DNA concentration of $P$. mirabilis showed 1.7-fold increase, showing a lower increase rate than control, but there was no significant difference compared to the control $(p=0.1537)$. In addition, the inhibitory effect of HAB under aerobic condition had the same significance as the $\mathrm{pH}$ results (Table 2) under aerobic condition.

It has been reported that Saccharomyces spp. strains produce organic acids during their growth [38]. However, as the acid-producing ability of $\mathrm{SB}$ was superior to that of SC [21], it seemed that the SB group had significantly decreased the $\mathrm{pH}$ of the manure compared to other groups, under all conditions, and was highly effective in the inhibition of $P$. mirabilis.

This suggests that $\mathrm{pH}$ changes in livestock manure are not only determined by the chemical actions of the manure constituents, but also by the growth and activities of microorganisms inducing environmental changes.

\section{Changes in ammonia gas emission from manure by yeast treatment}

The emission characteristics of ammonia gas in manure by yeast treatment were analyzed by the acid trapping of ammonia among the volatile gases and the indophenol method (Fig. 5). Ammonia emission patterns were similar to those of typical emissions from soil fertilized with urea nitrogen $[29,39]$. The cumulative ammonia emissions during the analysis period were $841.43 \pm 38.36$, $642.99 \pm 45.91$, and $829.27 \pm 56.80 \mathrm{mg} / \mathrm{kg}$ in the control, SB, and SC groups, respectively, while the SB group significantly reduced ammonia gas emissions by about $25 \%$ compared to the control $(p<0.05)$. Conversely, the treatment of SC compared with SB did not show any reduction effects. It was considered that the $\mathrm{pH}$ reduction and growth inhibition of $\mathrm{SB}$ against $P$. mirabilis, an aerobic ammonia-producing bacterium, positively affected reductions in ammonia gas emissions.

Ammonia emission is difficult to be directly compared due to various influence by environmental conditions such as manure composition, water content, temperature, and microflora. According to the study of Park et al. [29], however, it was reported that the amount of ammonia produced by urea fertilization in the soil decreased in proportion to the amount of mixed microbial treatment. As such, studies related to ammonia emission reduction by microbial treatment have been recently reported [29, $32]$, and in this aspect of utility, this study attempted to predict the reduction mechanism by effective single microbial treatment. Furthermore, since SB in this study is Saccharomyces spp., which is used as a probiotic for livestock, it may be present in feces through ingestion of animals. Therefore, we suggest that SB could not only increases livestock productivity but also reduces ammonia emissions.

Recently, fine dust has become an increasingly serious problem, and many studies have been reported regarding microorganisms that can effectively reduce ammonia emissions. However, most studies have focused on nitrogen conversion by microbial metabolism [30-32], and there has been insufficient research regarding the
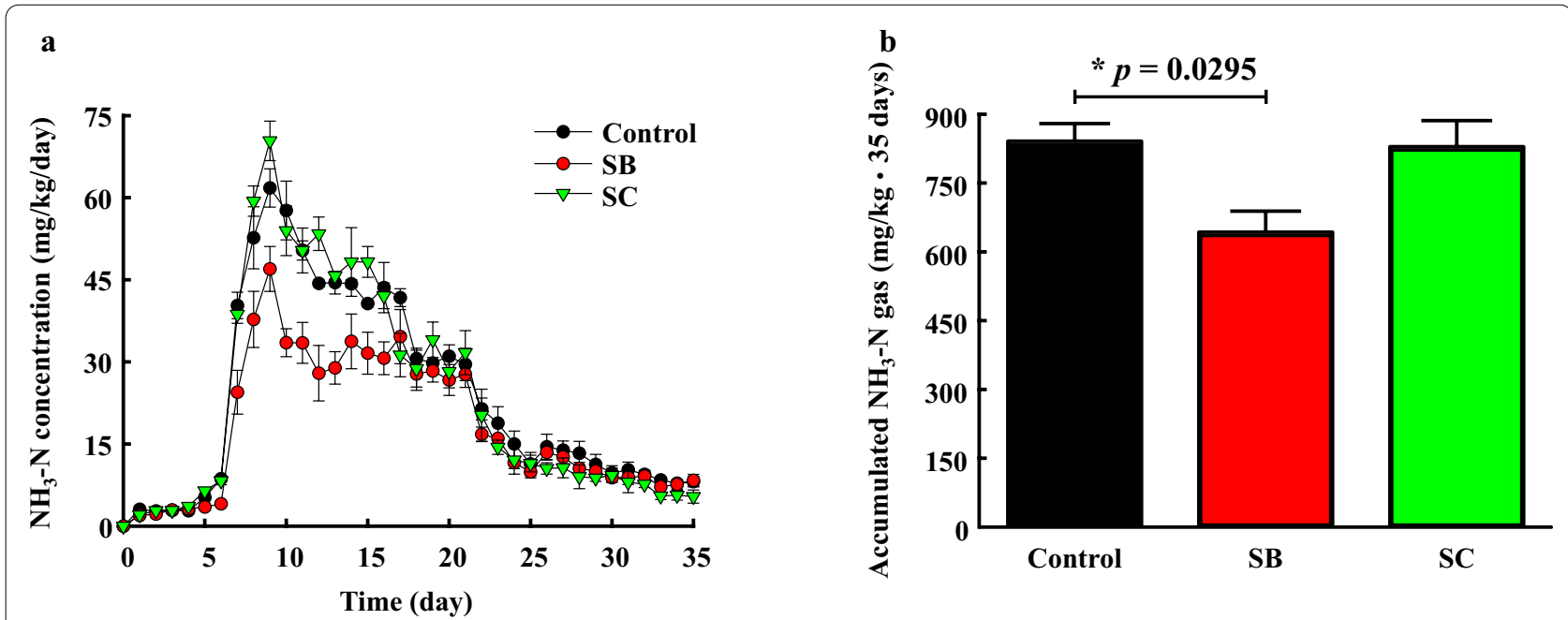

Fig. 5 Changes in $\mathrm{NH}_{3}$ gas emissions and accumulated ammonia gas in $100 \mathrm{~g}$ of livestock manure by treatment with yeasts. SB, Saccharomyces boulardii CNCM I-1079; SC, Saccharomyces cerevisiae KCTC 7107. Error bars represent the standard error $(n=3)$. a Daily amount of ammonia gas emissions, $\mathbf{b}$ accumulated amount of ammonia gas over 35 days. ${ }^{*} p<0.05$, compared between control and SB groups, indicates statistical significance (control vs. SB: $f$-value $=1.43$, degree of freedom $(D F)=4, t$-value $=3.32, p=0.0295$; control vs. SC: $f$-value $=2.19, D F=4, t-v a l u e=0.18$, $p=0.8678)$ 
characteristics of microbial ammonia gas production. In summary, this study clarified the possibility that SB can have positive effects on ammonia emission reduction by utilization of ammonia and the repression of environmental factors that affect ammonia emission. Furthermore, if observation on the changing factors is accompanied, it is expected that it can contributed to the research on reducing ammonia emission through microbial inhibitors and broadening the scope of utilization of SB which is already being used for industrial purposes.

\section{Acknowledgements}

This work was carried out with the support of "Cooperative Research Program for Agriculture Science and Technology Development (Project No. PJ01425303)" Rural Development Administration, Republic of Korea.

\section{Authors' contributions}

S-IK, WH, and Y-JK designed and conducted the experiment as well as wrote the manuscript. S-JL analyzed changes of $\mathrm{pH}$ in the manure by microbial treatment. B-KH and $\mathrm{H}-\mathrm{GL}$ inspired the overall research and revised the final manuscript. All authors read and approved the final manuscript.

\section{Competing interests}

The authors declare that they have no competing interests.

\begin{abstract}
Author details
1 Department of Food and Biotechnology, Korea University, Sejong 30019 , Republic of Korea. ${ }^{2}$ Department of Food Science and Engineering, Seowon University, Cheongju 28674, Republic of Korea. ${ }^{3}$ Department of Animal Science and Technology, Konkuk University, Seoul 05029, Republic of Korea.
\end{abstract}

Received: 19 November 2020 Accepted: 24 February 2021 Published online: 10 March 2021

\section{References}

1. Shin DW, Joo HS, Seo EJ, Kim CY (2017) Management strategies to reduce PM-2.5 emission: emphasis-ammonia. Korea Environment Institute (KEI) $1-89$

2. National Institute for Environmental Research (NIER, Korea) (2017) National Air Pollutants Emission Service, Air Pollutant Emission Statistics

3. European Environment Agency (EEA, Copenhagen, Denmark) (2016) EMEP/EEA Air Pollutant Emission Inventory Guidebook

4. McCrory DF, Hobbs PJ (2001) Additives to reduce ammonia and odor emissions from livestock wastes: a review. J Environ Qual 30(2):345-355

5. Sigurdarson JJ, Svane S, Karring H (2018) The molecular processes of urea hydrolysis in relation to ammonia emissions from agriculture. Rev Environ Sci Bio Technol 17(2):241-258

6. Vince A, Dawson AM, Park N, Grady F (1973) Ammonia production by intestinal bacteria. Gut 14(3):171-177

7. Whitehead TR, Cotta MA (2004) Isolation and identification of hyperammonia producing bacteria from swine manure storage pits. Curr Microbiol 48(1):20-26

8. Zhou S, Zhang X, Liao X, Wu Y, Mi J, Wang Y (2019) Effect of different proportions of three microbial agents on ammonia mitigation during the composting of layer manure. Molecules 24(13):2513

9. Arogo J, Westerman P, Heber A, Robarge W, Classen J (2002) Ammonia Emissions from Animal Feeding Operations. Animal Agriculture and the Environment: National Center for Manure and Animal Waste Management White Papers

10. Pinder RW, Adams PJ, Pandis SN (2007) Ammonia emission controls as a cost-effective strategy for reducing atmospheric particulate matter in the Eastern United States. Environ Sci Technol 41(2):380-386

11. Kim HH, Ha DM, Lee JY, Shin HS, Song Jl, Kim DH (2017) Effects of physico-chemical treatment on odor reduction of swine farm. Ann Animal Res Sci 28(2):64-71
12. Li H, Xin H, Burns $R$ (2006) Reduction of ammonia emission from stored poultry manure using additives: zeolite, $\mathrm{Al}^{+}{ }^{+}$Clear, Ferix $^{-3}$ and PLT. American Society of Agricultural and Biological Engineers, St. Joseph, MI

13. Roca-Mesa H, Sendra S, Mas A, Beltran G, Torija MJ (2020) Nitrogen preferences during alcoholic fermentation of different non-Saccharomyces yeasts of oenological interest. Microorganisms 8(2):157

14. Martínez-Moreno R, Quirós M, Morales P, Gonzalez R (2014) New insights into the advantages of ammonium as a winemaking nutrient. Int J Food Microbiol 177:128-135

15. Li Y, Wei G, Chen J (2004) Glutathione: a review on biotechnological production. Appl Microbiol Biotechnol 66:233-242

16. Lazo-Vélez MA, Serna-Saldívar SO, Rosales-Medina MF, Tinoco-Alvear M, Briones-García M (2018) Application of Saccharomyces cerevisiae var. boulardii in food processing: a review. J Appl Microbiol 125(4):943-951

17. Czerucka D, Piche T, Rampal P (2007) Review article: yeast as probioticsSaccharomyces boulardii. Aliment Pharmacol Ther 26(6):767-778

18. Theurer ME, Fox JT, Aguilar A, Nielsen H, Simpson J, Lawrence TE (2019) Effect of live yeast (Saccharomyces cerevisiae boulardii CNCM I-1079) feed additive on health and growth parameters of high-risk heifers in a commercial feedlot. Bovine Practitioner 53(2):117-127

19. Singu BD, Bhushette PR, Annapure US (2020) Thermo-tolerant Saccharomyces cerevisiae var. boulardii coated cornflakes as a potential probiotic vehicle. Food Bioscience 36:100668

20. Moon JE, Heo W, Lee SH, Lee SH, Lee HG, Lee JH, Kim YJ (2020) Trehalose protects the probiotic yeast Saccharomyces boulardii against oxidative stress-induced cell death. J Microbiol Biotechnol 30(1):54-61

21. Offei B, Vandecruys P, De Graeve S, Foulquié-Moreno MR, Thevelein JM (2018) Unique genetic basis of the distinct antibiotic potency of high acetic acid production in the probiotic yeast Saccharomyces cerevisiae var. boulardii. Genome Res 29(9):1478-1494

22. Rima H, Steve L, Ismail F (2012) Antimicrobial and probiotic properties of yeasts: from fundamental to novel applications. Front Microbiol 3:421

23. National Institute for Environmental Research (NIER, Korea) (2017) Standard Methods for the Examination of Water Pollution ES 04355.1C, Ammonium Nitrogen

24. Hierro N, Esteve-Zarzoso B, González A, Mas A, Guillamón JM (2006) Realtime quantitative PCR (QPCR) and reverse transcription-QPCR for detection and enumeration of total yeasts in wine. Appl Environ Microbiol 72(11):7148-7155

25. Chang HW, Nam YD, Sung Y, Kim KH, Roh SW, Yoon JH, An KG, Bae JW (2008) Quantitative real time PCR assays for the enumeration of Saccharomyces cerevisiae and the Saccharomyces sensu stricto complex in human feces. J Microbiol Methods 71:191-201

26. Kabeerdoss J, Ferdous S, Balamurugan R, Mechenro J, Vidya R, Santhanam S, Jana AK, Ramakrishna BS (2013) Development of the gut microbiota in southern Indian infants from birth to 6 months: a molecular analysis. J Nutr Sci 2:e18

27. Zhang W, Zongliang N, Yin K, Liu P, Chen L (2012) Quick identification and quantification of Proteus mirabilis by polymerase chain reaction (PCR) assays. Ann Microbiol 63:683-689

28. Bokulich NA, Ohta M, Richardson PM, Mills DA (2013) Monitoring seasonal changes in Winery-Resident Microbiota. PLoS ONE 8(6):e66437

29. Park JH, Lee SL, Hwang SW, Eom JH, Kim SH, Kang SW, Cho JS, Seo DC (2020) Characteristics of ammonia gas emissions from soybean cultivation soils treated with mixed microorganisms. Appl Biol Chem 63:20

30. Chen P, Li J, Li QX, Wang Y, Li S, Ren T, Wang L (2012) Simultaneous heterotrophic nitrification and aerobic denitrification by bacterium Rhodococcus sp. CPZ24. Biores Technol 116:266-270

31. Yang XP, Wang SM, Zhang DW, Zhou LX (2011) Isolation and nitrogen removal characteristics of an aerobic heterotrophic nitrifying-denitrifying bacterium, Bacillus subtilis A1. Biores Technol 102(2):854-862

32. Shimaya C, Hashimoto T (2011) Isolation and characterization of novel thermophilic nitrifying Bacillus sp. from compost. Soil Sci Plant Nutr 57(1):150-156

33. Kurosawa H, Nomura N, Tanaka H (1989) Ethanol production from starch by a coimmobilized mixed culture system of Aspergillus awamori and Saccharomyces cerevisiae. Biotechnol Bioeng 33(6):716-723

34. Koutsokali M, Valahas M (2020) Anaerobic and aerobic respiration in yeast: small-scale variations on a classic laboratory activity. J Chem Educ 97(4):1041-1047 
35. van Kempen TA (2001) Dietary adipic acid reduces ammonia emission from swine excreta. J Anim Sci 79(9):2412-2417

36. Kavanagh I, Burchill W, Healy MG, Fenton O, Krol DJ, Lanigan GJ (2019) Mitigation of ammonia and greenhouse gas emissions from stored cattle slurry using acidifiers and chemical amendments. J Clean Prod 237:117822

37. Tomicic Z, Colovic R, Cabarkapa I, Vukmirovic D, Djuragic O, Tomicic R (2016) Beneficial properties of probiotic yeast Saccharomyces boulardii. Food Feed Res 43(2):103-110

38. Ramon-Portugal F, Seiller I, Taillandier P, Favarel JL, Nepveu F, Strehaiano P (1999) Kinetics of production and consumption of organic acids during alcoholic fermentation by Saccharomyces cerevisae. Food Technol Biotechnol 37(4):235-240

39. Asing J, Saggar S, Singh J, Bolan N (2008) Assessment of nitrogen losses from urea and an organic manure with and without nitrification inhibitor dicyandiamide, applied to lettuce under glasshouse conditions. Aust J Soil Res 46(7):535-541

\section{Publisher's Note}

Springer Nature remains neutral with regard to jurisdictional claims in published maps and institutional affiliations.

\section{Submit your manuscript to a SpringerOpen ${ }^{\circ}$ journal and benefit from:}

- Convenient online submission

- Rigorous peer review

- Open access: articles freely available online

- High visibility within the field

- Retaining the copyright to your article

Submit your next manuscript at $\boldsymbol{\nabla}$ springeropen.com 